\title{
Beyond the Rhetoric: Maternal, Newborn and Child Survival in Nepal
}

\section{Sharma G ${ }^{1}$, Pandey SR ${ }^{2}$}

${ }^{1}$ Centre for Maternal, Adolescent, Reproductive and Child Health, Department of Infectious Disease Epidemiology, London School of Hygiene and Tropical Medicine, London, U.K

${ }^{2}$ Public Health Professional, Kathmandu, Nepal.

Received: July 18, 2015 ; Accepted: December 15, 2015

Nepal has performed exceptionally in improving reproductive, maternal and child health outcomes over the past two decades. In this article, we discuss these achievements and outline a vision for the future of maternal, newborn and child survival in Nepal after the era of the Millennium Development Goals. On the pathway towards quality universal health care services for all, we propose strengthening of health information systems, gradual health system reforms, improvement of existing facility based services, development of integrated service delivery models, improved technical and managerial capacity at district and facility levels. Elimination of all preventable causes of maternal, newborn and child deaths in Nepal should be our collective aspirational goal.

Keywords: child; maternal; Nepal; newborn; quality of care.

\section{INTRODUCTION}

Nepal's progress towards the 2015 Millennium Development Goals (MDGs) target for maternal and child survival has received considerable global attention and admiration. ${ }^{1}$ Nepal successfully reduced the maternal mortality ratio from 539 to 229 per 100,000 live births between 1996 and 2011.,3 Impressive gains were also made in child survival with declines in under-five mortality from 118 to 54 per 1000 live births (54\% reduction) and infant mortality from 79 to 46 per 1000 (41\% reduction) between 1996- 2011.2-4 During the same time period, neonatal mortality reduced by $34 \%$ from 50 to 33 per 1000 live births..$^{2-4}$

The UNICEF, A Promise Renewed progress report (2014) also acknowledges Nepal as one of the ten countries with the largest absolute decline in neonatal mortality rate from 1990-2013..$^{5}$ These gains have been possible against a backdrop of increasing institutional deliveries (45\%), ${ }^{3,6}$ reduced total fertility rates (2.6), ${ }^{3,6}$ improved modern contraceptive use $(43 \%),{ }^{3,6}$ improved caesarean section rates $(4.6 \%),{ }^{3}$ improved coverage of antenatal care visits from

\section{CORRESPONDENCE}

Dr Gaurav Sharma

Maternal, Adolescent, Reproductive and Child Health (MARCH) Centre, Department of Infectious Disease Epidemiology, London School of Hygiene and Tropical Medicine, London, UK

Email: drsharmag@gmail.com

Phone: + 44(0) 7810031297 skilled providers $(58.3 \%)^{3}$ and overall improved female literacy (secondary education $36 \%$ in 2011). ${ }^{3}$ Table 1 outlines the timeline for selected maternal and newborn health $(\mathrm{MNH})$ programme and policy inputs to the health sector in Nepal. Health was central to the MDGs and thus commanded a greater level of attention from policymakers, planners, academics and donors. Within the health sector, maternal and child survival benefitted enormously by having high calibre dedicated leaders, an extensive local knowledge base and long standing programmatic experience. This allowed the Ministry of Health and Population (MoHP) and partners to systematically implement effective interventions at scale such as birth preparedness and complication readiness, expanding birthing centres, home based maternal and newborn care interventions including community case management strategies, immunization, vitamin A, iron and folic acid supplementation and others. Despite many successes, some limitations of the MDG era are now obvious. Disparities in maternal and child health outcomes have increased amongst different ethnic groups, poorer wealth quintiles, those living in rural areas and marginalised communities. ${ }^{7}$ Some vertical silos emerged limiting health system strengthening efforts and promotion of integrated programmatic approaches for Reproductive, Maternal, Newborn and Child Health (RMNCH). 
Table 1. Timeline showing selected policy and programmes for maternal and newborn health in Nepal.

\begin{tabular}{|c|c|c|c|c|}
\hline 1997 & \multicolumn{4}{|c|}{ Nepal Safe Motherhood project } \\
\hline 2001 & \multicolumn{4}{|c|}{ Nepal Family Health Project } \\
\hline 2002 & \multicolumn{2}{|c|}{ National safe motherhood plan (2002-2017) } & \multirow{2}{*}{\multicolumn{2}{|c|}{$\begin{array}{l}\text { Abortion legalised } \\
\text { Strategic plan for Human resources for } \\
\text { health }\end{array}$}} \\
\hline 2003 & $\begin{array}{l}\text { National safe abortion } \\
\text { Policy }\end{array}$ & Nepal health sector strategy & & \\
\hline 2004 & $\begin{array}{l}\text { National nutrition Policy } \\
\text { and Strategy }\end{array}$ & $\begin{array}{l}\text { Health Sector strategy: An agenda } \\
\text { for reform }\end{array}$ & \multicolumn{2}{|c|}{$\begin{array}{l}\text { Nepal Health Sector programme: } \\
\text { Implementation Plan (NSHP- IP) }\end{array}$} \\
\hline 2005 & $\begin{array}{l}\text { Nepal Red Cross Society } \\
\text { Health Policy }\end{array}$ & $\begin{array}{l}\text { Revised Safe Delivery Incentive } \\
\text { Programme }\end{array}$ & \multicolumn{2}{|c|}{ Support to Safe Motherhood project } \\
\hline 2006 & $\begin{array}{l}\text { Health sector } \\
\text { Information System } \\
\text { National Strategy }\end{array}$ & $\begin{array}{l}\text { Nepal Health Sector Programme: } \\
\text { Implementation Plan (2004-2009) }\end{array}$ & $\begin{array}{l}\text { National } \\
\text { Policy on } \\
\text { Skilled birth } \\
\text { attendants }\end{array}$ & $\begin{array}{l}\text { National Safe } \\
\text { Motherhood and } \\
\text { newborn health long } \\
\text { term plan }\end{array}$ \\
\hline 2007 & Free Health Care Policy & $\begin{array}{l}\text { Implementation guidelines on } \\
\text { ARSH }\end{array}$ & \multicolumn{2}{|c|}{ Nepal Family Health Project- 2} \\
\hline 2008 & \multicolumn{4}{|c|}{ National Nutrition Policy and Strategy } \\
\hline 2009 & Aama programme & $\begin{array}{l}\text { Community Based Newborn Care } \\
\text { package }\end{array}$ & \multicolumn{2}{|c|}{$\begin{array}{l}\text { Five year Operational Plan for In-service } \\
\text { training of skilled birth attendants }\end{array}$} \\
\hline 2010 & \multicolumn{4}{|c|}{ Nepal Health Sector Implementation Plan -2 } \\
\hline 2011 & \multicolumn{4}{|c|}{ Nepal Health Sector Support Programme (NHSSP) } \\
\hline 2012 & \multicolumn{2}{|c|}{ FCHV programme revised strategy } & \multicolumn{2}{|c|}{$\begin{array}{l}\text { Multi-sectoral plan for accelerating the } \\
\text { reduction of maternal and child under } \\
\text { nutrition in Nepal (2013-2017) }\end{array}$} \\
\hline 2013 & \multicolumn{4}{|c|}{ Guidelines for Community health insurance of Nepal } \\
\hline
\end{tabular}

Nationally, the era of the MDGs translated to a direct increase in funding to maternal, newborn and child health. The overall national health budget consistently increased from the year 2000 and peaked at $7.4 \%$ of the total annual budget in 2010/11. Government reports suggest that between 2000/01 to $2008 / 09$, the health expenditure in Nepal increased by $11.8 \%$ in nominal terms, and $4.9 \%$ in real terms. ${ }^{8}$ The budget allocated to the health sector was the highest in 2014/15 at NRs. 33.5 billion (USD equivalent 352 million). ${ }^{9} \quad$ Significant investments have also been made by External Development Partners (EDPs) in Nepal. In 2011, EDP contributions made up approximately $39 \%$ of the health budget ${ }^{10}$ and a large portion of that was devoted to maternal and child health. A Sector Wide Approach was also adopted to improve aid effectiveness and strengthen coordination amongst partners which seems to be yielding positive results in the health sector. ${ }^{11}$

With that background, we now outline our vision for the future of maternal and newborn health and identify five areas that seem to be the most critical for future progress after the 2015 MDG era in Nepal.

\section{Health Information System}

As the existing national Health Management Information System (HMIS) only captures facility- based events such as births or deaths and selected outreach activities such as immunizations, Nepal continues to rely on large scale household surveys conducted at five year intervals or on projections obtained through advanced modelling techniques to effectively monitor progress against $\mathrm{RMNCH}$ targets. ${ }^{12}$ This can often prove problematic, hamper efficient decision making and lead to confusion at the national level. For example, significant discrepancies exist between the latest global maternal mortality ratio estimates obtained from different sources. The 2014 WHO estimates indicate that the maternal mortality ratio for Nepal is 190 (Confidence Interval: 110-340) per 100, 000 live births which translates to approximately 1,100 maternal deaths in Nepal. ${ }^{13}$ Whereas, the Institute for Health Metrics and Evaluation (IHME) 2014 estimates indicate that the maternal mortality ratio is 272.3 (CI: 190.9 to 363.5 ) which translates to 1,588 maternal deaths. ${ }^{14}$ Varied estimates such as these create confusion amongst national planners who need reliable data for decisionmaking (Figure 1). 
Figure 1. Trends in Maternal mortality ratios (per 100, 000 live births) between 1990-2015 in Nepal.

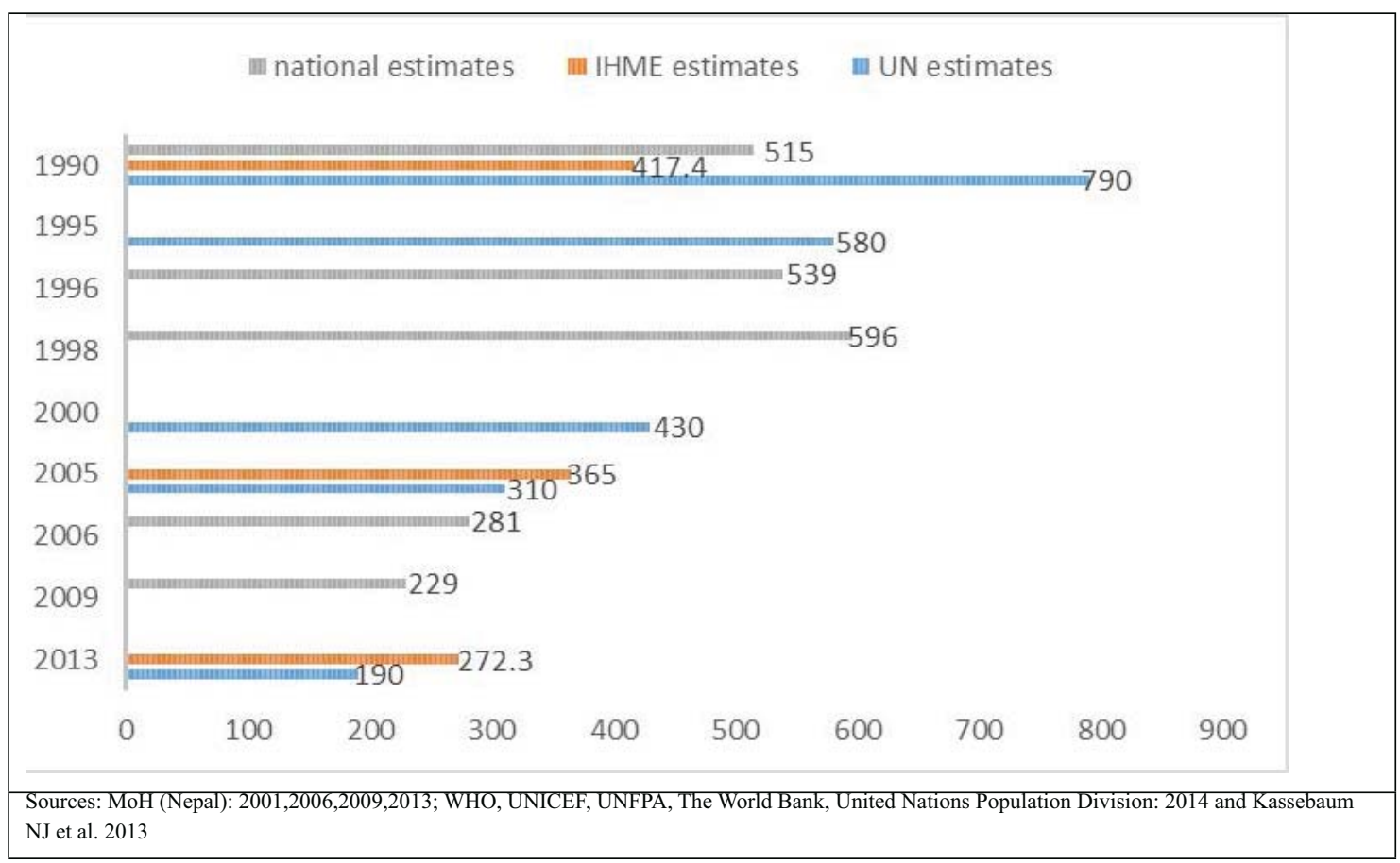

To reduce such instances, three investments need to be made in Nepal. First, develop national vital registration systems so that all births and deaths are registered in Nepal. This should be framed as a rights based issue to demonstrate that health and survival of mothers and newborns is valued in Nepalese society. ${ }^{15}$ Second; establish and strengthen routine maternal, perinatal and child death and surveillance systems so that all maternal, neonatal and child deaths are accurately monitored in real time. This will require high-level political commitment, an appropriate legal framework, development of appropriate national guidelines, financial support, capacity building of health professionals and involvement of professional bodies. Third, invest in developing national capacity for evidence-based programme management especially at the district level so that epidemiological data is effectively utilised for designing an appropriate response. Mechanisms to collect an improved set of $\mathrm{RMNCH}$ indicators that measure content and quality of care; disaggregated by ethnicity, geography, gender, social status and client characteristics need to be developed, validated and institutionalised.

This will help in developing appropriate and flexible, context based plans and support tailored implementation of integrated RMNCH interventions.

\section{Universal Health Coverage}

There is an increasing realisation amongst policy makers and practitioners that health systems in Nepal should be reformed along the principles of universal access to primary health care including free of cost RMNCH services, reduction of catastrophic health expenses and identification of alternate health financing mechanisms. Out of pocket expenses are still exorbitant in Nepal $(55.8 \% \text { in } 2005 / 06)^{8}$ leading to catastrophic expenses, crippling debt and a vicious cycle of poverty for families. Although selected $\mathrm{MCH}$ services, including management of both normal and complicated deliveries (except care for newborn complications), is provided free of cost, additional services and drugs (currently 40 separate medicines are provided free of cost) are needed. The solution lies in developing innovating financing mechanisms so that $\mathrm{RMNCH}$ services can be provided free of cost under an umbrella of universal health coverage (UHC). Given Nepal's size, population dynamics and the existing socio-economic context, UHC is a possibility, if appropriate, alternative revenue generation and financing streams are identified and effective policies and programmes are designed. The newly developed Nepal Health Insurance Policy 
2013 will also be able to reduce financial barriers, if implemented and scaled up carefully. ${ }^{16}$ Further, we need to effectively utilise available resources, prioritise investments in preventive and promotive care and improve existing national health care infrastructure. Despite good absorption rates of the health budget (in high $80 \mathrm{~s} \%$ ), many inefficiencies such as duplication of efforts, poor coordination amongst stakeholders, ineffective, multi-sectoral, integrated delivery mechanisms still exist. A culture of evidence-based management in public health based on reliable epidemiological data is needed.

\section{Quality of Facility Based Care}

Although, community-based programmes have been hugely successful in Nepal through the efforts of female community health volunteers, these must be considered as interim strategies formulated to achieve quick-wins while longer term efforts such as human resource development, health system strengthening and behaviour change efforts are ongoing. There is no shortcut to developing high quality, facility-based obstetric and neonatal care services especially high quality maternity services that offer triple returns on investment through the prevention of stillbirths, reduction of neonatal and maternal deaths. ${ }^{17}$ There is also evidence to suggest that an obstetric transition is occurring in countries ${ }^{18}$ and that there is a proportionate increase in the indirect causes of maternal ${ }^{13}$ and neonatal deaths which require specialised facility based services. High quality maternity services involves providing minimum level of care to all pregnant women and their newborn babies and a higher level of care for those who need it. ${ }^{19}$ Planning should, therefore, consider existing geographical realities, availability of staff, drug, equipment, infrastructure, referral and transportation capacity, availability of emergency surgery, blood transfusion capability and availability of specialized care for mothers and babies. Care seeking practices, case load and case mix at maternity facilities are also important for planning purposes. High quality maternity care require provision of timely, reliable, equitable, efficient, compassionate, patient-centred care, with application of evidence based standards to ensure patient safety and health worker satisfaction. ${ }^{19}$ Delivery of such services should also maintain sound managerial and financial performance standards and improve quality of existing services for women and children. ${ }^{19}$ WHO estimates indicate that Nepal has only 6.4 doctors, nurses and midwives per 10,000 population compared to WHO critical threshold of 22.8 per 10,000 population. ${ }^{20}$ This demonstrates the need to urgently scale up production, deployment and retention of skilled teams of health workers involved in the provision of maternity services.

\section{Integration of RMNCH}

Integration of $\mathrm{RMNCH}$ is an issue that has also gained prominence over the past decade in Nepal. The Lancet series first advocated for a continuum of care for RMNCH care that spans the home, community, health centre and the hospital. ${ }^{21}$ Integration is defined as a "variety of managerial, operational changes to health systems to bring together inputs, delivery, management, and organization of particular service functions to improve the service in relation to efficiency and quality, thereby maximizing use of resources and opportunities". ${ }^{22}$ Although, simple theoretically, integration is a complex operational and programmatic issue. If done correctly, there is evidence to suggest that integration could lead to long term savings, facilitate optimal use of health workers and promote client centred services such as provision of a range of $\mathrm{RMNCH}$ services at the point of care. ${ }^{22}$ Small-scale pilot efforts have tried to integrate Family Planning (FP) and MCH services with immunization services in Nepal but this has not been tried on a larger scale. Integrated approaches to training of health workers and monitoring and evaluation efforts may also help to streamline programme implementation. Small-scale feasibility studies could be established to identify effective and feasible models for integrated RMNCH service delivery in Nepal. This would also advance implementation science and the use of robust evaluation methods in Nepal.

\section{Capacity Strengthening}

National capacity needs to be strengthened so that the public health managers have the necessary epidemiological, managerial and technical competencies. Competency based training methodologies need to be institutionalised and quality of existing trainings needs to be stringently monitored. Innovative capacity strengthening and retention strategies for health workers could be tested. ${ }^{19}$ Although task shifting to FCHVs has proved successful to a certain degree, alternative human resource development strategies are needed so that adequately trained cadres can provide facility based 
essential obstetric and neonatal care services. Care must also be placed to ensure that FCHVs are not overburdened and sustainable financing mechanisms for FCHV incentives are developed.

\section{CONCLUSIONS}

Despite long-standing political unrest, governance, management and implementation challenges, the Government of Nepal has done exceptionally well in improving RMNCH outcomes over the past decade. At present, efforts are ongoing to develop a new Nepal Health Sector Programme (NHSP-3) with an intention of aligning NHSP-3 priorities with the recently released National Health Policy (2014/2071). ${ }^{16}$ Nepal is also a signatory to newer global commitments such as the Every Woman Every Child initiative, FP 2020, Ending Preventable Maternal Mortality and also contributed to the Every Newborn Action Plan.

Going forward, prioritising financial and technical investments into the health sector for universal health coverage could reap huge dividends for overall socioeconomic development in Nepal. Systemic health system reforms will be needed along this pathway to maximise efficiency, effectiveness and transparency in the health sector. These efforts should be guided by data obtained from strengthened information systems that help to accurately identify and prevent avoidable deaths of mothers, newborn and children in Nepal. Emphasising quality of care across community and facility based services are essential to make further improvements. Designing efficient and integrated

\section{REFERENCES}

1. Pradhan YV, Upreti SR, Pratap KCN, K CA, Khadka N, Syed U, et al. Newborn survival in Nepal: a decade of change and future implications. Health Policy Plan. 2012;27 Suppl 3(iii57-iii71):iii57-71

2. MoHP [Nepal], New ERA, Macro International Inc. Nepal Demographic and Health Survey 2006. Kathmandu: Ministry of Health and Population, New ERA, and MACRO International Inc; 2007.

3. MoHP [Nepal], New ERA Ltd., Macro I. Nepal Demographic and Health Survey 2011: Preliminary report draft tables. Kathmandu, Nepal and Calverton, MD: Ministry of Health and Population [Nepal], New ERA Ltd., and ICF Macro; 2011.

4. MoH [Nepal], New ERA, ORC Macro. 2002. Nepal Demographic and Health Survey 2001. Kathmandu, Nepal and Calverton, MD: Family Health Division, Ministry of Health; New ERA; and ORC Macro; 2001.

5. UNICEF. Committing to child survival: a promise renewed - progress report, 2012. UNICEF, New York. http://www. apromiserenewed.org/files/APR_Progress_Report_2012_ final web.pdf. service delivery models (where appropriate) could be an easy first step in the process. Strengthening the capacity of health workers by providing better support systems and creating enabling environments for evidence based practice are important. National guidelines for the delivery and organization of care need to be revisited and/ or developed based on the principles of ensuring patient safety, improved care experiences, promotion of respectful care models and improved quality of facility based services. Finally, people should be empowered to participate in decision-making processes so that a culture of zero tolerance towards corruption, malpractice and misappropriation of public resources is established. Political accountability and fiscal transparency are essential to establish credibility with the electorate. More than ever, we need dedicated and committed national champions to end all preventable maternal, newborn and child deaths in Nepal.

\section{ACKNOWLEDGEMENTS}

The authors would like to thank Dr. Stephen Hodgins for his detailed review and thoughtful comments on an earlier version of the draft.

\section{DISCLOSURE}

The authors report no conflicts of interest in this work. No violation of human rights and safety.

Funding: Nil

6. Ministry of Health and Population, Department of Health Services. Teku, Kathmandu, Nepal. Annual Report 20122013.

7. Pandey JP, Dhakal MR, Karki S, Poudel P, Pradhan MS. Maternal and child health in Nepal: the effects of caste, ethnicity, and regional identity: further analysis of the 2011 Nepal demographic and health survey 2013.

8. Shrestha BR, Gauchan Y, Gautam GS, Baral P. Nepal national health accounts, 2006/0007-2008/2009. Kathmandu: Health Economics and Financing Unit, Ministry of Health and Population; 2012. http://apps. who.int/nha/country/npl/ nepalnha.pdf. accessed 02.03.14.

9. Ministry of Health and Population, Government of Nepal. Annual budget for fiscal year 2070-2071 (2014/15). Ram Shah Path, Kathmandu, Nepal. 2014.

10. Tiwari S LS, Baral P, Adhikari R, Poudel LR, Thapa MB, Lievens T. NHSSP Budget Analysis 2011/12. 2012.

11. Vaillancourt D. Do Health Sector Wide Approaches Achieve Results. Emerging Evidence and Lessons from Six Countries Washington, DC: Independent Evaluation Group-The World Bank. 2009;4(2009):4 
12. Sharma G. Maternal, Perinatal and Neonatal Mortality in South-East Asia Region. Asian J Epidemiol. 2012;5(1):1-14

13. WHO U. UNFPA, The World Bank, United Nations Population Division. Trends in maternal mortality: 1990 to 2013. Estimates by WHO, UNICEF. UNFPA, The World Bank and the United Nations Population Division. Geneva: World Health Organization; 2014.

14. Kassebaum NJ, Bertozzi-Villa A, Coggeshall MS, Shackelford KA, Steiner C, Heuton KR, et al. Global, regional, and national levels and causes of maternal mortality during 1990 2013: a systematic analysis for the Global Burden of Disease Study 2013. Lancet. 2014;384(9947):980-1004

15. Graham WJ, Hussein J. Universal reporting of maternal mortality: an achievable goal? Int J Gynaecol Obstet: the official journal of the International Federation of Gynaecology and Obstetrics. 2006 ;94(3):234-42

16. Government of Nepal. Nepal Health Insurance policy. 2013

17. Lawn JE, Blencowe H, Pattinson R, Cousens S, Kumar R, Ibiebele I, et al. Stillbirths: Where? When? Why? How to make the data count? Lancet. 2011;377(9775):1448-63
18. Souza JP, Tuncalp O, Vogel JP, Bohren M, Widmer M, Oladapo OT, et al. Obstetric transition: the pathway towards ending preventable maternal deaths. BJOG. 2014 Mar;121 Suppl 1 (s1):1-4

19. Sharma G, Mathai M, Dickson KE, Weeks A, Hofmeyr G, Lavender T, et al. Quality care during labour and birth: a multicountry analysis of health system bottlenecks and potential solutions. BMC Pregnancy Childbirth. 2015;15(Suppl 2):S2

20. World Health Organization. WHO Atlas of the Health Workforce. 2010

21. Kerber KJ, de Graft-Johnson JE, Bhutta ZA, Okong P, Starrs A, Lawn JE. Continuum of care for maternal, newborn, and child health: from slogan to service delivery. Lancet. 2007;370(9595):1358-69

22. Briggs CJ GP. Strategies for integrating primary health services in middle and low-income countries at the point of delivery (Review). Cochrane Database of Systematic Reviews. 2006 